\title{
Erratum to: Analysis of Power Deposition on Heat Load Components for EAST Neutral Beam Injector
}

\author{
Yongjian $\mathrm{Xu} \cdot$ Chundong $\mathrm{Hu} \cdot$ Sheng Liu \\ Ling Yu $\cdot$ NBI Group
}

Published online: 7 October 2014

(c) Springer Science+Business Media New York 2014

\section{Erratum to: J Fusion Energ}

DOI 10.1007/s10894-014-9746-x

In the original version of this article, unfortunately the caption of Fig. 6 has been erroneously published as

Fig. 6 Beam power deposition distribution on the heat load components (Orange: Theoretical results, Blue: Experiment results; Vacc $=60 \mathrm{kV}$ )

And the correct caption is as follows:

Fig. 6 Beam power deposition distribution on the heat load components (Orange: Theoretical results, Blue: Experiment results; Vacc $=50 \mathrm{kV}$ )

The online version of the original article can be found under doi:10.1007/s10894-014-9746-x.

Y. Xu $(\varangle) \cdot$ C. Hu $\cdot$ S. Liu $\cdot$ L. Yu

Institute of Plasma Physics, Chinese Academy of Sciences,

Hefei 230031, China

e-mail: yjxu@ipp.ac.cn 